\title{
Effect of typical clay upon the dispersion performance of polycarboxylate superplasticizer
}

\author{
Long xiong, Guangjun Zheng, Yao Bi, Chengfei Fu \\ China Construction Ready Mixed Concrete Co. Ltd, Wuhan 430205, China, \\ xionglong1987@126.com
}

Keywords: clay; polycarboxylate superplasticizer; Viscosity; dispersion; adsorption

\begin{abstract}
The effect of three typical commercial clays (Na-MMT, Illite and Kaolin) upon the dispersion of polycarboxylate (PCE) was investigated by mini slump test and viscosity analysis. PCE adsorption on clays or cement was determined by method of total organic carbon. Mini slump test results showed adding more than $2 \%$ Na-MMT or adding $4 \%$ kaolin will significantly affect the fluidity of cement pastes, but Illite affect the fluidity of cement pastes slightly. The viscosity test shown in order to achieve the same plastic viscosity( $0.15 \%$ PCE dosage), PCE is employed at a dosage of $0.45 \%, 0.24 \%$ and $0.2 \%$ bwoc respectively as the case of adding $2 \%$ Na-MMT, kaolin and Illite. The total organic carbon shown that the order of PCE sorbed amounts is Na-MMT, Kaolin, cement and Illite.
\end{abstract}

\section{Introduction}

Polycarboxylate superplasticizer (PCE) has become an important component in the production of high performance concrete [1-3]. While with the enlargement of the application area, it was found that the concrete raw materials have obvious effect on the performance of polycarboxylate superplasticizer, especially the existence of clay in aggregate [4-8]. It may cause decline in strength and durability of concrete, and significantly increase the shrinkage of concrete. Besides this, excessive clay minerals may seriously affect the dispersion properties of polycarboxylate superplasticizer. In this case, the sensitivity of polycarboxylate superplasticizer to clay has greatly restricted its generalization and application [9]. Therefore, it is necessary to study the mechanism of the interaction of clay minerals with polycarboxylate superplasticizer. In this paper, the law of the impact of clay minerals on the properties of polycarboxylate superplasticizer was mainly studied by mini slump test and viscosity analysis, PCE adsorption on clays or cement was determined by method of total organic carbon.

\section{Material and methods}

\subsection{Materials}

A Cement $42.5 \mathrm{R}$ was used supplied by huaxin Co., Ltd. The specific surface area of $3500 \mathrm{~cm}^{2} / \mathrm{g}$ was measured using a Blainein strument (Toni Technik, Berlin/Germany).

Three typical commercial clay sample of Na-MMT, Illite and Kaolin (Aladdin Reagent Shanghai Co., Ltd.) were used as per obtained. Their phase compositions as obtained by quantitative X-ray diffraction (BrukerD8 advance instrument, software Topas 4.0) were presented in Table 1.

Table 1 Phase compositions of CEM and Three typical commercial clays as determined by XRD

\begin{tabular}{ccccccccccc}
\hline Name & $\mathrm{Si}_{2} \mathrm{O}_{3}$ & $\mathrm{Al}_{2} \mathrm{O}_{3}$ & $\mathrm{MgO}$ & $\mathrm{Fe}_{2} \mathrm{O}_{3}$ & $\mathrm{CaO}$ & $\mathrm{Na}_{2} \mathrm{O}$ & $\mathrm{K}_{2} \mathrm{O}$ & $\mathrm{TiO}_{2}$ & $\mathrm{SO}_{3}$ & Loss \\
\hline Cement & 21.20 & 5.55 & 0.89 & 3.46 & 63.68 & $/$ & $/$ & $/$ & 3.01 & 4.59 \\
Na-MMT & 75.92 & 13.05 & 2.37 & 2.15 & 3.00 & 2.15 & 0.20 & 0.23 & 0 & 15.69 \\
Illite & 75.92 & 13.05 & 2.37 & 2.15 & 3.00 & 2.15 & 0.20 & 0.23 & 0 & 15.69 \\
Kaolin & 58.05 & 25.70 & 0.68 & 0.68 & 1.16 & 1.41 & 1.58 & 1.00 & 0.37 & 12.76 \\
\hline
\end{tabular}

The PCE was synthesized according to previous study by aqueous free radical copolymerization of acrylic acid (AA) and polyoxyethylene ether (TPEG-2400) at molar ratios of 3.5. Methallylsulfonic acid was used as chain transfer agent. The chemical formula of the PCE is 
presented in Fig.1.

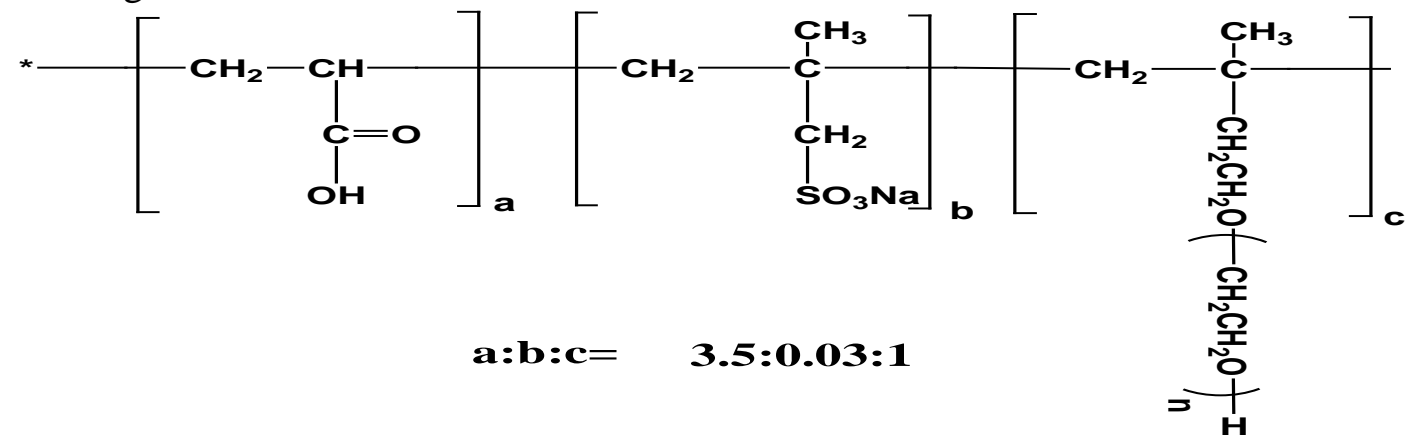

Fig.1 Chemical structure of the PCE samples employed in the study

\subsection{Mini slump test}

Test of the fluidity of cement pastes added with superplasticizer and three typical clays were under the national standard GB 8077-2000 "methods for testing uniformity of concrete mixture", the w/c ratio was 0.29 and the dosage of the PCE was $0.15 \%$ (by percent Weight based on solids cement).

\subsection{Viscosity analysis}

Test of the viscosity of cement pastes added with superplasticizer and three typical clays were investigated by digital rotary viscometer with the speed of $12 \mathrm{r} / \mathrm{min}$ (NDJ-5S, Shanghai NiRun Intelligent Technology Co., Ltd.).

\subsection{Sorption experiments}

PCE adsorption on clays or cement was determined by method of total organic carbon. Details of the test and calculation method could be found in Ref. 10 .

\section{Results and discussion}

\subsection{The effect of the typical clays on the fluidity of cement pastes}

To ascertain the effect of clay on PCE, the Spread flow of a cement slurry (w/c $=0.29)$ containing different bwoc of clays were investigated and shown in Fig. 2. According to this data, three kinds of clay affect the dispersion performance of PCE differently. The influence order is Na-MMT, kaolin, Illite. Adding more than 2\% Na-MMT or adding $4 \%$ kaolin will significantly affect the fluidity of cement pastes, but Illite affect the fluidity of cement pastes slightly. The Slump loss data of cement pastes also show the same trend. After adding the same quality of the three kinds of clay, Na-MMT has a bigger fluidity loss of cement pastes.

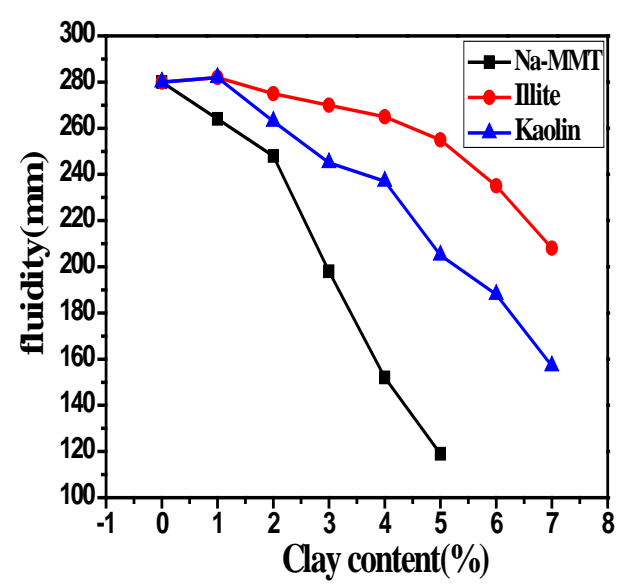

Fig.2 Spread flow of a cement slurry (w/c $=0.29$ ) containing different bwoc of clays

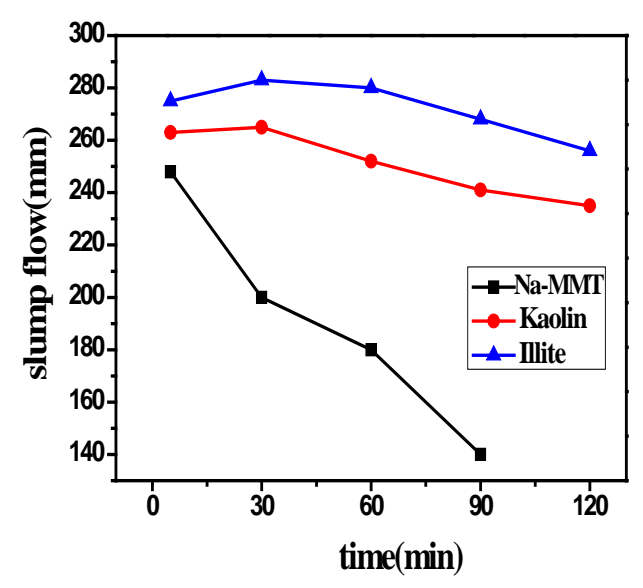

Fig.3 Slump loss behavior of a cement slurry $(\mathrm{w} / \mathrm{c}=0.29)$ containing $4 \%$ bwoc of clays 


\subsection{The effect of the typical clays on the viscosity of cement pastes}

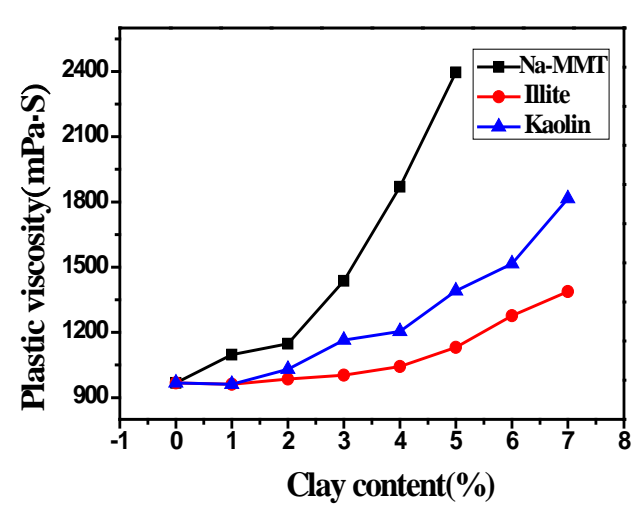

Fig.4 Plastic viscosity with varied clays content

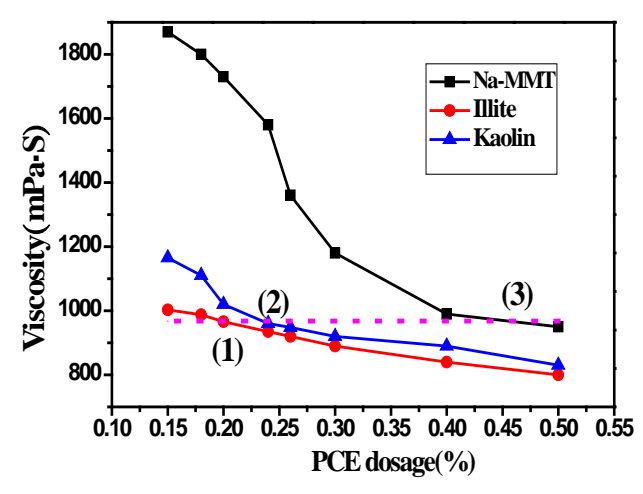

Fig.5 Plastic viscosity containing varied PCE dosage

To further investigate the effect of clay on PCE, the viscosity of the cement paste is used as a measure. Thus, plastic viscosity with varied clays content and PCE dosage were displayed in Fig. 4 and Fig.5. It was found that when adding 2\% Na-MMT or adding $4 \%$ kaolin, plastic viscosity is remarkably increased. While, plastic viscosity has the nothing important change until adding 5\% Illite. According to Fig.5, plastic viscosity is $968 \mathrm{mPs} \cdot \mathrm{S}$ in the case of $0.15 \%$ PCE dosage and without clay. In order to achieve the same plastic viscosity, PCE dosage of cement paste with adding $2 \%$ Na-MMT is necessary to reach $4.5 \%$. Such a dosage is equivalent to three times as a case of without clay. As the case of adding $2 \%$ kaolin and Illite, PCE is employed at a dosage of $0.24 \%$ and $0.2 \%$ bwoc, respectively.

\subsection{PCE adsorption in cement/clay system}

To further ascertain the effect of clay on PCE, the sorbed amounts of PCE in cement paste 4wt.\% of three typical clays were investigated in Fig.5. As expected, the order of PCE sorbed amounts is Na-MMT, Kaolin, cement and Illite. It confirms strong interaction between PCE and Na-MMT, plausibly higher than with cement. It can be seen that in a cementitious system, a considerable amount of PCE can be consumed by a relatively minor amount of Na-MMT contaminant. While illite is relatively insensitive to PCE, Which coincides with the aforementioned.

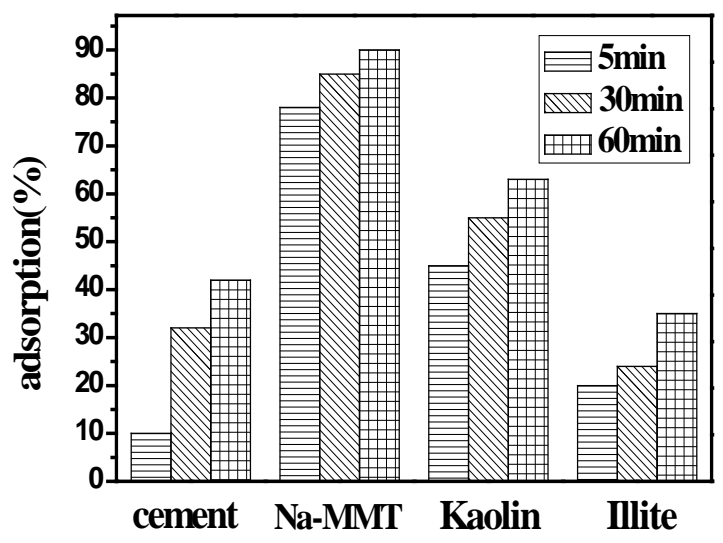

Fig.6 Adsorption of PC in cement and three typical clays

\section{Conclusion}

This work confirms that three kinds of clay affect the dispersion performance of PCE differently. The influence order is Na-MMT, kaolin, Illite. The viscosity test shown that plastic viscosity is 968 
$\mathrm{mPa} \cdot \mathrm{S}$ in the case of $0.15 \%$ PCE dosage and without clay. In order to achieve the same plastic viscosity, PCE is employed at a dosage of $0.45 \%, 0.24 \%$ and $0.2 \%$ bwoc respectively as the case of adding 2\% Na-MMT, kaolin and Illite. The total organic carbon shown that the order of sorbed amounts is Na-MMT, Kaolin, cement and Illite as the case of PCE in cement paste and 4wt. \% of three typical clays.

\section{References}

[1] Ran. Q, Somasundaran. P, Miao. C, et al. Effect of the length of the side chains of comb-like copolymer dispersants on dispersion and rheological properties of concentrated cement suspensions [J]. Journal of Colloid and Interface Science. 2009, 336(2): 624-633.

[2] Plank J, Dai Z M, Keller H, et al. Fundamental mechanisms for polycarboxylate intercalation into $\mathrm{C}_{3} \mathrm{~A}$ hydrate phases and the role of sulfate present in cement [J]. Cement and Concrete Research , 2010, 40(1): 45 - 57.

[3] Ota A, Sugiyama T, Tanaka Y. Fluidizing mechanism and application of polycarboxylatete-based superlasticizers [C]. $5^{\text {th }}$ Canmet/Cai Int Conf on superplasticizers and Other Chemical Adimixture in Concrete, 1997, 359 - 379.

[4] LEI L, PLANK J. A concept for a polycarboxylate superplasticizer possessing enhanced clay tolerance [J]. Cement and Concrete Research, 2012(42): 1299-1306.

[5] Munoz J F, Tejedor M I. Detection of aggregate clay coatings and impacts on concrete [J]. ACI Materials Journal, 2010, 107(4): 387 - 295.

[6] Liu, X. Mo, C. Zhang, D. Sun, C. Mu, Swelling Inhibition by polyglycols in montmorillonite dispersion [J], Journal of Dispersion Science and Technology, 2006, 25(1):63 66.

[7] Norvell J K, Stewart J G, Maria c, et al. Influence of clays and claysized particles on concrete performance[J]. Journal of Materials in Civil Engineering, 2007, 19(12): 1053 -1059.

[8] Suter J L, Coveney P V, et al. Computer simulation on study of the materials properties of intercalated and exfoliated poly(ethylene)glycol clay nanocomposites [J]. Soft Material, 2009, 5(9): 2239 - 2251.

[9] Atarashi D. Interaction between superplasticizers and clay minerals [J]. Japan Cement Association, 2005, 58(6): 287 - 392.

[10] NG S, PLANK J. Interaction mechanisms between Na montmorillonite clay and MPEG-based polycarboxylate superplasticizers [J]. Cement and Concrete Research, 2012(42): 847-854. 